\title{
Crónica
}

\section{Nuestro pasado con las niguas}

José Néstor Valencia Zuluaga *

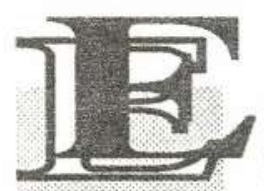

xtinguidas, quizás de un todo, por los insecticidas y el uso general del calzado, la generación actual no sabe ni lo que fueron ni lo que significaron las ántora niguas en los siglos anteriores de nuestra historia.

Locierto es que una buena parte de los entretelones cotidianos y $\sin$ brillo de esa historia menuda que no se escribe, tiene mucho que ver con dichos

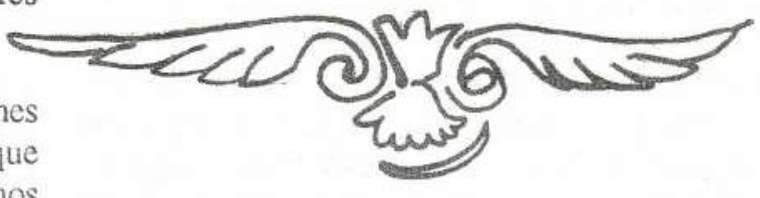
insectos, así se los deje atrás como los guijarros del camino.

Infortunadamente, de las niguas no existe, que scpamos, página alguna en nuestra literatura costumbrista. Qué tal un cuadro nigüista en la pluma de Carrasquilla, con su gracejo y agudeza? Quizás ese vacío se deba al temor reverencial causado por el rubor de quienes padecieron las niguas.

De ellas habian los cronistas de la conquista tales como Fray Pedro Aguado, Fray Pedro Simón y el Padre Gumilla. Los soldados españoles, muchos de ellos vencedores en renombradas batallas de Europa, se vieron humillados lastimosamente por estos diminutos insectos, que bien pueden pasar por el ojo de una aguja. Cuántas veces, la piquiña ardiente, la fiebre local, la inflamación de los dedos de los pies, los inmovilizaron hasta no poder ni calzar sus dóciles abarcas. Alguno de los cronistas cuenta cómo un conquistador, afligido

por las niguas, imploró la piedad de una india, quien con un alfiler de oro se las extrajo pacientemente. Desde entonces, la historia patria también con pies niguateros, corre hasta alcanzar los nuestros.

Juan de Castellanos ${ }^{1}$ habla de la casa grande donde los indios de Popayán celebraban sus fiestas. Tan grande era, que sus estantes eran en número de cuatrocientos, y ninguno de ellos podía: «ser de dos españoles abrazado». Allí se alojaron los conquistadores, pero con tan mala suerte que :

'Juan de Castellanos, Elegías de Varones Ilustres de Indias, Tercera parte, Canto Tercero.

* Nació en Pensilvania (Caldas), Licenciado en Teología de la Universidad Gregoriana de Roma y actual Investigador del Instituto Caro y Cuervo. 
«vieras sacudir las plantas

y dar mil brincos al caballo laxo porque niguas y pulgas fueron tantas que no se vió reposo más escaso; y así cubiertos hasta las gargantas, los echan del lugar más que de paso, de manera que les hicieron guerra, en vez de los vecinos de la tierra»

Pero, cómo fue nuestro pasado con las niguas ? Se puede decir que pertenecieron las niguas a la época de las maderas, cuando las casas se construían con maderos cortados de las selvas. Los tablados, losentresuelos, los sótanos, la cercanía de los animales domésticos favorecían la cría de las niguas. De improviso, la piquiña irritante en los pies, acusaba la presencia de las niguas bajo las uñas o la epidermis de los talones. El temor de tener que ser pinchados por una navaja bien afilada, o una aguja, para extraerlas, no ya con alfiler de oro, daba tiempo a que hiciesen sus nidos y se multiplicasen en cantidades de huevecillos blancos, alcanzando a extenderse en forma de colonias, llamadas «jarreteras». Entonces podían producir la deformación de los pies y su torcedura, dando origen al tipo social del "patojo», llamado así por su caminado pendular como el de los patos.

Las niguas tenían actividad nocturna, incitada por el tibio de la cama. Era un placer cruel rascar y más rascar los pies; y una dulce amargura hacerlo contra una estera * lo más áspera posible. Lo desastroso era que el rascar incitaba el más picar. No obstante, semejante situación podía ocurrirse en vigilia, cuando se usaban los zapatos para asistir a misa de fiesta. El calor del zapato las alborotaba, pero sin el recurso de poderse rascar libremente.

Una vez extraídas las niguas, había que taponar el pequeño orificio so pena de que otras niguas hallaran la entrada libre. Ello se hacía con sebo o alguna untura amarga; había varias recetas según la región.

La «nigua enconada» era un caso más grave, puestoque no sólamente picaba sinoque dolía. Su descuido podía llegar a ser peligroso. Horacio Quiroga narra en uno de sus cuentos la muerte de su personaje, por haber permanecido sumergido en el cieno, teniendo "piches» e sus pies. La infección propagada en todo el cuerpo llegó a causar la muerte de muchos españoles de la conquista.

Mas, volviendo ahablardel «patojo». habrá que decir que era el quedado, no por eso el apocado de la familia. Quien llegaba a ser adulto con los pies torcidos por las niguas, no pudiendo, por consiguiente usar zapatos, ya tenía cortado su porvenir. Sería el hazmerreir y hasta el baldón de la familia. En compensación, existió una literatura oral de cuentos de «patojos» en los que se desplegaba con visos de picaresca, el ingenio del personaje. Es lástima que este género de literatura ya no encuentre narradores memoristas.

Y ya que hablamos de ingenio, se ha pensado no sin razón, que las niguas fueron un incentivo de lucidez mental.

Cuando nosotros rascábamos niguas en nuestra niñez de pies desnudos, allá por los años de 1937, apareció un artículo de Charles Benoit en «The New York Times», sobre: "Las niguas - El ingenio y el talento», traducción de Avelino Paz, en "Antología Genial de los Patojos», por Otón Sánchez, 1983, págs. 98-108. Talleres Editoriales del Departamento del Cauca.

* «Estera», tejido grueso; en nuestro caso, de alguna fibra, especialmente del tallo del plátano, usada como colchón para dormir. 
En dicho artículo se da la razón científica del aserto popular, en tesis sustentada por el doctor Pierre Crouchet ante la Academia de Medicina de París. La tesis fue el fruto de largos años de investigación. Efectivamente, el doctor Crouchet fue comisionado del gobierno francés para investigar las endemias de las colonias francesas en el Africa; pero, estuvo también con los egiptólogos ingleses que descubrieron las tumbas de los faraones; igualmente hizo investigaciones en Méjico, y posteriormente en Popayán, «La tierra clásica de las niguas». En nuestra ciudad colombiana estudió más de dos mil casos. Y las conclusiones fueron asombrosas: fueron niguateros los faraones, los soberanos aztecas, muchos de nuestros aventajados conquistadores, y la lista interminable de excelentes payaneses, que por su inteligencia y sus dotes, hicieron honor a las niguas. Inclusive, la obra cumbre de la literatura española, El Ingenioso Hidalgo, habría sido el resultado de un contagio de niguas, ocasionado por un amigo de Cervantes que murió en su casa, habiendo llevado el mal que contrajo, precisamente de Popayán.

No por nada, en el Viejo Caldas, se dice de la persona insinuante en las relaciones humanas, que es más entradora que una nigua salamineña.

Con literatura o sin ella, las niguas participaron cotidianamente en la rutina de los días, que han culminado recientemente en los quinientos años del descubrimiento de América. Esa historia no se ha escrito, pero se tradujo en genio y talento de muchos hombres grandes de Colombia y del mundo.

(Nuestro reconocimiento para Doña Mary Trujillo, quien nos facilitó el artículo de Charles Benoit.)

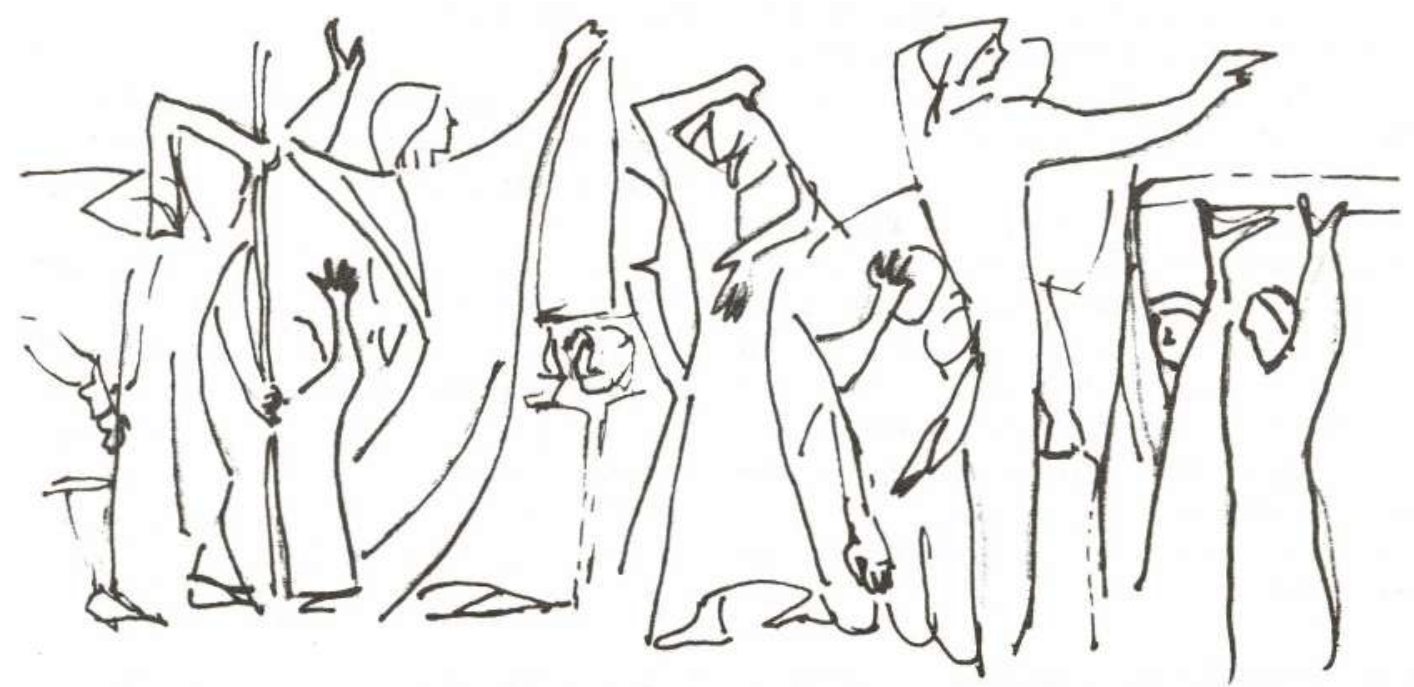

Ilustración de Carlos A. Hoyos M., inspirada en el mural del maestro Guillermo Botero. 